\title{
O sábio-aprendiz e o efêmero lugar da escrita: para uma ética da inventividade acadêmica
}

Tomás Vallera'

Ana Luísa Paz'

\section{Resumo}

Este texto procura abrir a possibilidade de se discutir, em conjunto, os processos próprios da escrita, vividos individualmente, mas partilhados na condição comum de alunos de doutoramento. Tratase de promover uma discussão intensiva em torno dos bloqueios históricos que atingem a produção e a circulação dos textos acadêmicos, a partir de conceitos emanados de duas teses em história da educação. Nomeadamente, identificou-se em cada uma delas instrumentos singulares que realizam essa ligação entre o passado e o presente da ontologia da aprendizagem, a saber, os conceitos de polícia e de gênio. Apresenta-se a desnaturalização dessas noções do presente como solução local, artesanal e inteiramente irrepetível destinada a suspender a permanência histórica de figuras incapacitadas pela posição de autoridade e de ingenuidade em que se instalaram no processo de escrita inventiva. Em primeiro lugar, procurou-se pensar um conceito de polícia que permitisse analisar o problema da autoridade no sábio. Em segundo lugar, pretendeuse identificar no gênio um aprendiz ingênuo. A partir desse duplo deslocamento, extraímos generalizações imputáveis à nossa escrita, contornando a segurança de quem fala (sábio) e o medo de quem escreve (aprendiz) com a personagem ambivalente do sábioaprendiz, imagem do estatuto efêmero do pesquisador e do escritor recém-legitimado ainda por consagrar. 0 debate apoia-se no convite lançado pela literatura pós-estruturalista ao equacionar a vida enquanto obra de arte, traduzido aqui na possibilidade de refletir criticamente a respeito da virtualidade de se ser, simultaneamente, o sujeito e o objeto do seu próprio texto.

\section{Palavras-chave}

Pós-graduação - Escrita acadêmica - Inventividade.

I- Universidade de Lisboa, Lisboa, Portugal.

Contatos: tomasvallera@gmail.com; apaz@campus.ul.pt 


\title{
The scholar-apprentice and the ephemeral locus of writing: for an ethics of academic inventiveness
}

Tomás Vallera'

Ana Luísa Paz'

\begin{abstract}
This article attempts to open up the possibility of debating the writing process as both an individual and shared academic experience. It proposes a discussion on the historically contingent hindrances that affect the production and circulation of academic texts, based on specific concepts drawn from two dissertations in the field of history of education. Both provide conceptual tools aimed at displaying the connection between past and present ontology of education: the notions of police and genius. The denaturalization of these contemporary notions is used as a topical, tailor-made solution devised to temporarily suspend the historical endurance of two familiar characters: the scholar and the apprentice. It is further argued that these polarized and complementary personae are incapacitated by the positions of authority and ingenuity in which they have been cast in relation to the creative process. First, a particular concept of police is devised to analyze the subject of the scholar's authority. Secondly, the genius is identified as a naïve apprentice. As a result of this exercise, it became possible to circumvent both the certainty of the scholar's prescriptive discourse and the inexperienced student's fear of writing by resorting to the ambivalent image of the scholar-apprentice: the ephemeral status of the writer when conducting his research. This dialog is rooted in the post-structural perception of life as a work of art, interpreted as the ability to critically ponder the possibility of simultaneously embodying the subject and the object of one's own writing.
\end{abstract}

\section{Keywords}

Graduate studies - Academic research - Inventiveness.

I- Universidade de Lisboa, Lisboa, Portugal.

Contacts: tomasvallera@gmail.com; apaz@campus.ul.pt 
Somos ao mesmo tempo o sábio e o aprendiz da tese que escrevemos: espera-se de nós a produção de um saber, mas não conhecemos ainda esse saber, é necessário partir em busca dele. Este texto presume que a construção de uma tese implica um gesto de afastamento em relação ao que já é conhecido, o esboço de um movimento de sentido contrário a um dizer banal e recidivo. Assim, o sábio-aprendiz - alguém que estuda um problema específico e só em nome dele se autoriza a falar - depara-se na escrita da sua tese com dificuldades comuns a sábios e aprendizes. Longe de tentar sistematizar aquilo que deve distinguir essas duas personagens entre as quais vai oscilando, o investigador permite-se apenas discorrer a respeito daquilo que inevitavelmente as aproxima: o desejo de escrita. Tomando como ideia fundadora a vontade de escrita, para tornar mais presente tanto aquilo que o aflige como aquilo a que almeja, vê-se impelido a formular um problema universal do gesto criativo.

Esse sábio-aprendiz convoca outras figuras concetuais quando elas mesmas aludem à peculiar condição de sujeito da escrita. Vêse acompanhado nessas questões por uma série de autores que lhe permitem imaginar formas inventivas de combate aos problemas da escrita acadêmica - Espinosa, Nietzsche, Kafka, Blanchot, Deleuze, Barthes, Foucault. No encontro com eles, numa apropriação assumidamente parcial e utilitária, o próprio pensamento vai-se fazendo mais potente e inclinado à problematização.

Acompanhados de uma utensilagem teórico-metodológica que pensa a escrita no seu exercício mesmo, ensaiamos um gesto de problematização unívoco, traçado a partir de pesquisas diferentes. Embora uma - A polícia como engenharia social da vida (1780-1834): a Casa Pia de Lisboa e a escolarização do órfão desvalido (VALLERA, 2012) - parta do esmiuçamento do conceito de polícia para o dilatar numa teorização geral e outra - Ensino da música em Portugal (1868-1930): uma história de pedagogia e do imaginário musical (PAZ, 2013) - use a ideia abstrata de gênio para analisar traços concretos do escolar, experimentamos, afinal, um mesmo olhar.

Trata-se sempre de mostrar, com essa tribo teórica, que a historiografia é menos a demonstração de uma verdade a desocultar e mais a criação de novas esferas para o pensamento. No limite, o próprio tempo histórico apresentase como criação e suspensão. Todo esse modo de escrita vive do princípio do encontro e do auxílio mútuo entre pensamentos, interligados por um artesanato delicado que não sobrevive ao finalizar de cada texto.

A confluência com os autores eleitos convida à criação de grupos de trabalho tecidos de raiz para enfrentar os bloqueios do processo criativo. Numa dobra dessa inspiração, instalamos uma célula combativa que vive do diálogo a quatro mãos em tempo limitado. Partimos, cada um de sua investigação, esperando que as fragilidades singulares potenciem uma comum produtividade reflexiva. Aqui, o consolo de não pensar sozinho participa numa pragmática e numa ética do processo de construção da escrita. Por todas essas razões, propomos um percurso em que a exigência do conclusivo dá lugar à experiência vívida do tangencial.

\section{A polícia da opinião: reflexões acerca da improdutividade na escrita acadêmica}

0 que se segue é uma reflexão em torno de duas interrogações que, emparelhadas, configuram um mesmo problema: Como ter uma ideia? Como esquivar-se a um dizer banal? Sugere-se, em primeiro lugar, uma interpelação ao desejo de escrita a partir da construção de uma ideia. Em segundo lugar, propõe-se uma abordagem à rarefação da escrita a partir do problema do dizer banal.

A composição de uma ideia a respeito da escola e de sua origem policial pressupôs o deslocamento a um tempo antes do nosso, onde o conceito de polícia se encontrava na fronteira entre o adjetivo e a função. A IntendênciaGeral da Polícia, fundadora da Casa Pia de Lisboa - estabelecimento criado em 1780 por 
Pina Manique como um misto de prisão, casas de correção e oficinas de lavores para órfãos, prostitutas e jovens delinquentes - marca o momento histórico em que o conceito de polícia foi definitivamente institucionalizado. Até ao século XVIII, em Portugal, esse conceito não definia um sujeito único, um objeto exclusivo ou uma área de conhecimento delimitada. Pela diversidade de campos em que era aplicado, devolve-nos apenas a ideia geral de uma relação harmoniosa entre os ditames da autoridade e os modos de se conduzir dos sujeitos ou grupos sobre os quais ela se exercia. Tínhamos, assim, a polícia das nações, a polícia cristã, a polícia dos mosteiros, a polícia da escrita (de cartas e missivas), a polícia do trato (na corte).

Quando Camões (2000, p. 463), no canto $\mathrm{X}$ dos Lusíadas, alude a uma Europa cristã "mais alta e clara que as outras em polícia”, refere-se não tanto às leis dos soberanos ou à conduta de um bom cristão, mas, sobretudo, a um bom casamento entre determinadas formas de governar e determinados modos de se conduzir: a isso se chamará mais tarde civilidade.

A Intendência-Geral da Polícia permite-nos refletir não tanto a propósito do nascimento da polícia enquanto força do Estado moderno ou, no inverso, a respeito de um modo absoluto de policiar que desapareceria definitivamente sob o regime liberal, mas acerca da institucionalização desses modos múltiplos de produzir a homogeneidade em determinados grupos populacionais. Incidir sobre o conceito de polícia tornar-se-ia, desse modo, uma perspetiva com vista a desinstitucionalizar e dessubjetivar uma história profundamente marcada pelo traçado evolutivo do problema da segurança pública e a tornar mais presentes, na sua estranheza, alguns dos mecanismos que aproximam o gesto educativo moderno - a escolarização - das estratégias de produção da conformidade. Construir uma ideia, por essa via, seria consentâneo com um exercício de autorreflexividade.

$\mathrm{Na}$ hipótese de investigação da tese A polícia como engenharia social da vida: a Casa Pia de Lisboa e a escolarização do órfão desvalido (1780-1834), o objeto de estudo foi-se constituindo como estratégia de aproximação a um conjunto de temas exógenos a uma historiografia tradicional da polícia. Essa historiografia pressupõe certos pontos de partida inquestionados, que formam desde logo a antecâmara de qualquer pesquisa: a cidade e a segurança pública; o Estado moderno e a formação do seu aparelho administrativo; o progresso histórico em direção a uma força policial moderna e razoável.

A operação consistiria em observar a polícia como tecnologia, o que significa que não se definiria a partir de um sujeito, uma função específica ou um saber especializado, mas que estaria ela própria envolvida nas lutas, nas regulamentações e nos processos de naturalização que constituem o próprio solo de onde brotam esses mesmos sujeitos, funções e saberes.

Para tornar mais claro esse campo tecnológico, foi necessário proceder às avessas, descrevendo o modo como se constituíram historicamente esses três vetores que enformam a nossa relação com o gesto policial: 1) a segurança pública como necessidade natural e intemporal de defender a sociedade combatendo os flagelos sociais; 2) o princípio segundo o qual o poder de policiar advém do Estado e é determinado pela estrutura e pelas caraterísticas desse Estado; e 3) a noção de que o bem, a civilização, as luzes, triunfam sobre o mal, a libertinagem e a ignorância, numa trajetória virtuosa e linear. Isso acontece por via de dois grandes conjuntos discursivos: i) o que se insurge contra a fraqueza moral, a ociosidade e as más inclinações naturais do homem; ii) o que protesta contra um regime de verdade alternativo, errado nas suas premissas, deletério para os homens e para a vida em sociedade. Daqui emergem duas figuras: o policial, que se dá por tarefa defrontar a transgressão na cidade independentemente da natureza dos regimes políticos; o homem de Estado e o revolucionário, figura dúplice que trava o combate às ideias perniciosas do adversário de acordo com uma lógica oposicional do poder. 
Poderíamos imaginar Diogo Inácio de Pina Manique, intendente-geral da polícia durante o reinado de D. Maria I (entre 1780 e 1805), como a figura que reúne historicamente os dois primeiros princípios da polícia: a luta contra o flagelo social e a polícia como derivação natural da autoridade e soberania do Estado moderno. 0 mais célebre intendente foi simultaneamente rigoroso defensor do ethos monárquico e minucioso detetor das condutas desviantes na cidade.

Não seria desacertado afirmar que o governo josefino foi o primeiro grande historiador da polícia, o fundador dessa narrativa diacrónica do desassossego público e das suas respostas institucionais. A compilação intitulada Leis a que se refere a da polícia, reunida no rescaldo do terremoto de 1755 como referência para um conjunto de medidas de emergência tomadas em contexto de catástrofe, seria assim o primeiro repositório dessa relação dialética da criminalidade com os poderes públicos. Esse compêndio seria de seguida anexado à Lei da Polícia de 1760, formando com ela - e fazendo nela culminar - uma história contínua do desregramento social e da insuficiência do sistema de quadrilheiros para o combater.

Desde essa pesquisa do Estado sobre si mesmo que a segunda metade do século XVIII nos legou - indo ao fundo dos arquivos recuperar uma narrativa de sucessivas frustrações e tornando, nesse mesmo gesto, legítima e sequencialmente lógica uma nova abordagem da arte de governar - que a história da polícia não mais se libertou desses dois princípios que a animam: 1) uma progressão linear que desde a Idade Média se faz em direção a um objetivo que, no entanto, nunca se consegue alcançar; 2) o momento de consumação, onde a emergência de estruturas fundamentais do Estado moderno possibilita a eclosão da verdadeira polícia, que havia sempre estado presente em condição embrionária, impedida de se desenvolver pela confusão própria das antigas leis. Desenvolvimento da administração da coroa no espaço urbano que culmina, por decreto real, com o estabelecimento de uma força policial profissional na cidade de Lisboa: o fım do sistema de quadrilheiros, a implantação da Intendência-Geral da Polícia (1760).

Está assim feita a articulação: ali onde se formam poderes de vocação pública, nasce a necessidade de garantir a tranquilidade de todos, e ali onde um Estado com caraterísticas modernas se constitui, cria-se a polícia como instituição independente, dotada de poderes específicos, formando um corpo de agentes que tem por função assegurar a segurança dos indivíduos integrados na coletividade. 0 devir polícia vem por arrasto ou como consequência de um devir moderno do Estado.

Um terceiro princípio vem juntar-se a esses dois. 0 seu período de gestação inicia-se no seguimento da revolta liberal do Porto e da guerra miguelista (1820 e 1828-1834), embora se constitua como discurso historiográfico apenas na passagem para o século XX. Determina essa interpretação que "a instituição da Intendência-Geral da Polícia [entra] em contradição com o sistema de governo constitucional da monarquia portuguesa”, devendo ser abolida, para que as comissões de que se encarregava fossem entregues a um serviço público "regularmente desempenhado por autoridades constitucionalmente estabelecidas" (SARMENTO, 1822, p. 50).

A imperfeita polícia é o produto e a marca de um Estado mal governado. Sob uma organização do Estado fundamentalmente errada nas suas premissas, a polícia não poderia senão representar uma modalidade injusta de governo: o braço armado de uma vontade de poder.

Porém, inserido numa lógica liberal-constitucional, o gesto policial irá, naturalmente, significar uma outra coisa. Um serviço público sob escrutínio de representantes eleitos não poderia ser análogo a uma força que, a pretexto de garantir a segurança pública, servia os interesses privados do príncipe. Desvirtuamento do Estado, lenda negra de Pina Manique. Nasce, em consequência, a iniciativa legislativa com vista a desmontar todo 
o aparelho megalômano da Intendência-Geral da Polícia ${ }^{1}$. As suas diversas competências serão descentralizadas e distribuídas por diferentes instituições (SARMENTO, 1822, p. 51).

A designação de polícia iria, nesse processo, ganhar o seu sentido contemporâneo. Perdendo alguns dos seus atributos para diferentes órgãos administrativos, conservaria aquilo que, daí em diante, se viria a confundir com a sua própria identidade: o não institucionalizado, o gesto proibitivo devidamente enquadrado no organograma do Estado democrático. Não mais o Estado de polícia, onde as atividades dos homens eram submetidas a um policiamento superestrutural, mas uma polícia que serve o Estado na área específica e bem delimitada da segurança pública.

Mas esse princípio da rejeição da polícia absolutista é complementado por um discurso de sentido inverso. Se é certo que o regime liberal condena com veemência o despotismo, na realidade, dispõe-se a elogiá-lo quando se trata de valores considerados absolutos, exógenos ao enfrentamento ideológico, como seja a ordem pública, a questão educativa ou a profilaxia urbana ${ }^{2}$.

Assim, à naturalidade da função e à originalidade do Estado viria aglutinar-se a ideia de que o destino da nação estaria indissociavelmente irmanado ao afloramento do progresso e da liberdade. E que, mesmo no caso extremo do déspota, era ainda assim possível ver a parte elucidada do seu espírito escapar-se em direção a um futuro promissor, seguindo o caminho das luzes, enquanto o velho edifício gótico se desmoronava na escuridão circundante.

Foram identificadas as traves-mestras que compõem a nossa ideia contemporânea de polícia, com os seus respectivos momentos de

1- "Semelhante estabelecimento [Intendência-Geral da Polícia] sempre me pareceu um monstro e um instituto perigosíssimo porque, debaixo de formas e aparências de legalidade, se opunha à justiça e à razão". (SARMENTO, 1822, p. 327)

2- "[...] [0] Intendente da Polícia Pina Manique, que tantos serviços prestou à cidade de Lisboa." (MARGIOCHI, 1898, p. 268); "Mande S. Exa. [... ] a dotação do material de ensino às escolas industriais, para que não se levante contra S. Exa. a memória de Pina Manique [...] que foi um grande homem..." (NOGUEIRA, 1903, p. 19) afloração na lei e no discurso historiográfico. Descrita essa homogeneização da narrativa histórica, importa compreender de que forma é que a ideia de polícia enquanto construção da conformidade poderia ser aplicada à escola. Essa noção abstrata, de cariz tecnológico, vai tomar a polícia não como instituição, sujeito coletivo ou modo de governar o Estado, mas como adjetivo designando a qualidade daquilo que é bem governado.

Esse efeito observável de um bom governo caraterizar-se-ia pela harmonia decorrente da conformidade entre a conduta dos governados e os objetivos de quem governa. Assim, a Intendência-Geral da Polícia não se confundiria com a polícia em si, mas configuraria um modelo institucional ativado no sentido de a alcançar. A polícia não mais como uma coisa que age, mas como algo que se persegue. Nessa persecução, vão ser reclamados para as práticas de governo instrumentos múltiplos de produção da homogeneidade. Desse ponto de vista, o que podemos observar com uma história da polícia é uma narrativa que associa a estratégia de enfrentamento da coroa contra os seus concorrentes na cidade (clero, nobreza, senado de Lisboa) - pregando as virtudes da segurança pública em detrimento dos males da jurisdição privativa - aos primeiros escritos referentes a uma engenharia social da vida (tratados de polícia do século XVIII) e aos modernos processos de escolarização. Três momentos de homogeneização que confluem na ação da Intendência-Geral da Polícia.

A Casa Pia de Lisboa foi sem dúvida o primeiro local privilegiado dessa experimentação orientada para um devir-escola em solo nacional. A escolarização da Casa Pia de Lisboa durante as suas primeiras décadas de existência constituiria, nesse sentido, não apenas um exemplo excepcional, como também um acontecimento pragmático em todos os níveis.

Não obstantes as dificuldades de financiamento de que sempre havia sofrido e os problemas logísticos que reiteradamente a assolavam - tendo sido desmantelada pelas tropas 
francesas quando da ocupação do Castelo de São Jorge, deficientemente realocada em 1811 no Convento do Desterro e, finalmente, refundada no Mosteiro dos Jerônimos em 1834 - essa instituição, originalmente pensada e tutelada por um organismo do Estado entretanto extinto e frequentemente vilipendiado, manteve-se obstinadamente de pé. 0 caráter tecnológico dos jogos de poder assegurou a esse modelo - o modelo escolar - uma absoluta impermeabilidade em relação às lógicas adversariais da trama política.

Os três princípios a que se submete o historiador da polícia - a polícia como necessidade ou emanação natural da sociedade, a polícia institucionalizada a partir da centralidade do Estado e o lugar privilegiado e moral do sujeito da narrativa - são os mesmos preconceitos que entram em jogo no debate público sobre as nossas instituições. Dentre essas instituições, destaca-se a escola.

A escola seria aquele objeto de estudo que, por há quase dois séculos nos ter vindo a fabricar enquanto sujeitos de conhecimento, teria se tornado ininteligivel do ponto de vista cognitivo. Nas palavras de Nietzsche, é precisamente aquilo que conhecemos e que vivemos com a naturalidade do que é vulgar que mais se obnubila a qualquer proposta de conhecimento: "o que é conhecido é habitual; e o habitual é o mais difícil de conhecer: isto é, de ver como problema [...] de ver como estranho, afastado, "fora de nós"” (NIETZSCHE, 2000, p. 242).

A escolarização aparece, então, como um processo duplamente policial, não só porque investe esforços na produção de populações crescentemente homogêneas, mas também porque, pela sua proximidade à experiência de vida do sujeito, talvez seja a instituição a propósito da qual proferimos, quotidianamente, o maior número de asserções impensadas.

Espinosa, enquanto personagem concetual invocada na escrita de Deleuze, oferece-nos uma possível chave de leitura para compreender a correlação entre o dizer trivial e a rarefação da escrita: a distinção entre consciência e pensamento. De acordo com esses autores, uma das caraterísticas da consciência é a de produzir formas de reflexão desajustadas:

as condições sob as quais conhecemos e temos consciência de nós próprios condenam-nos a ter ideias inadequadas, ideias confusas e mutiladas, efeitos separados das suas causas (DELEUZE, 1988, p. 19).

Imaginemos por um instante que essa ideia de consciência pudesse ser usada como ferramenta para diagosticar alguns aspectos da nossa contemporaneidade. Um dos aspectos que ela poderia iluminar seria a distribuição e o posicionamento de indivíduos ou grupos no debate público acerca de realidades institucionais.

Como formamos opinião sobre instituições como o Estado, a escola, a polícia, e as defendemos em público? Que ideias são essas trazidas a debate pelo legislador, pelo especialista ou pelo intelectual a respeito de assuntos que dizem respeito a todos nós? E de que modo nos identificamos com essas mesmas opiniões que versamos, em sintonia ou desacordo com um fazedor de opinião?

0 que mais nos impacta nessa interrogação - como formamos as opiniões que tomamos como nossas? - é o fato de ela ser tão pertinente na contemporaneidade de Espinosa, como o foi na de Deleuze e continua a ser hoje. É sempre possível indagar-se sobre esse assunto, independentemente da época ou da instituição em causa.

Nesse ponto, retomemos os dois pensadores. Como age, então, a consciência? A consciência vê os efeitos que sobre ela agem como causas da situação em que se encontra. Em vez de partir em busca das causas, "satisfaz a sua ignorância invertendo a ordem das coisas, tomando os efeitos por causas" (DELEUZE, 1988, p. 20; trad. nossa). Que significa isso? Significa que, por exemplo, nas discussões a respeito da escola pública, o especialista educacional, o intelectual - o cidadão - tendem a confundir os efeitos da instituição com as causas do seu atraso ou da sua ineficiência. No debate, muitas vezes acirrado, entre reformistas - que prometem 
um futuro melhor à escola e às necessidades de cada aluno, apoiando inovações nos métodos de ensino-aprendizagem - e críticos da escola afetiva e não-diretiva, geralmente associada ao termo pejorativo de "eduquês" - nostálgicos que idealizam a escola que frequentaram como inteiramente diferente; mais erudita e disciplinada do que a do presente - os dois campos digladiam argumentos que, tendo-se complementado durante gerações, estão de fato na base do sucesso e da expansão da instituição ao longo dos últimos dois séculos (Ó, 2003, p. 17-19).

No universo do debate de opiniões, da consciência espinosista, ou na sociedade dos adultos orientada para a ação eficaz - a que Kafka, segundo Bataille (1998, p. 136), opunha a puerilidade da escrita - as causas da decadência, da degenerescência, da ineficácia e da incompetência encontram-se sempre nos outros; no erro, na falta, na incapacidade dos outros. Será a partir desse efeito de incômodo da ação perniciosa dos outros sobre a consciência de quem a sofre que se determinará a causa ou a origem dos males que afetam a sociedade como um todo. Para os nostálgicos, é com a infeliz aliança entre educadores afetivos e nãodiretivos e uma infância sem rumo que nasce a crise da educação. Simetricamente, é com uma ideia de escola disciplinadora e autoritária, aliada a uma infância naturalmente ingênua e carenciada de luzes, que, para alguma expertise educativa, compromete-se qualquer processo de aprendizagem e se hipoteca irremediavelmente o futuro.

Reencontramos aqui o polícia, o homem de Estado autocrático e o revolucionário operando conjuntamente no interior do mesmo sujeito, denunciando nos alunos as perniciosas inclinações naturais dos homens sem rumo e nos adversários políticos 0 potencial devastador das ideias erradas e dos maus princípios educativos. Assim se tem vindo a conduzir o debate público nas nossas sociedades liberais-republicanas, onde uma nova personagem democrática veio ocupar o lugar dessas outras figuras arquetípicas do poder policial. Registre-se, enfim, nessa mesma polêmica, a existência de campos simétricos inamovíveis, inquietados com a eventualidade do desmoronamento moral e social e envolvidos numa disputa infındável pela alma do Estado a partir de posições de privilégio em que o lugar do sujeito na discussão se encontra antecipadamente determinado. Novamente: a fatalidade da desordem, a centralidade do Estado, o lugar privilegiado e moral do sujeito. Como se pode compreender, uma contenda levada a cabo nesses termos dificilmente origina um campo fértil para o pensamento, onde seja possível conjeturar novas conversas sobre a realidade educativa.

Esse universo dual é o nosso: falamos a linguagem da simetria. Perante essa esterilidade discursiva, uma das tarefas do pensamento seria justamente a de tentar descortinar, para lá daquilo que em consciência já dizemos, os pontos de proveniência e constituição da atmosfera altamente rarefeita que habitamos na ilusão da completude e da universalidade.

Num texto recente a respeito da violência escolar, publicado numa coluna de opinião, o filósofo José Gil (2010, p. 26) denuncia o "contexto geral de indisciplina" nas escolas, onde regularmente se assiste ao "desrespeito e violação das regras que devem assegurar uma aula normal e das regras tácitas de conduta de um ser em sociedade". Acrescenta que o clima "bárbaro" não permite muitas vezes "a mínima aprendizagem”. As razões: a "demissão dos pais", a "violência que atrai os adolescentes" e a "desagregação da autoridade dos professores". A causa profunda:

uma política laxista e ignorante do que é ensinar e educar, feita mais para reduzir as despesas do Estado e facilitar a vida aos pais do que para formar e transmitir conhecimento aos filhos. (GIL, 2010, p. 26)

Alerta-nos igualmente para o risco de profanação dos saberes que toda essa situação deixa adivinhar: 
Uma política que tanto deseja uma "sociedade do conhecimento" [...] pouco ou nada faz para impedir a desdignificação ou dessacralização do conhecimento. A violência que circula livremente nas escolas deriva também da ignorância dos alunos e da negligência (ignorância) dos responsáveis. (GIL, 2010, p. 26)

Sem dúvida que se trata de uma opinião comum, de vasta circulação, da qual nós próprios somos muitas vezes agentes e locutores. 0 que persiste no horizonte do pensável é, ainda, o sonho iluminista de uma escola pacificada, transmissora de um conhecimento imperturbado, onde a autoridade dos professores se exerce na justa medida em que, diante dela, se manifesta a disciplina dos alunos - transitando, por fim, entre uns e outros, um conhecimento dignificado por todos. 0 problema, que está longe de ser exclusivo do nosso tempo, é o fato de a escola persistir tal como é independentemente de qualquer opinião que sobre ela se tenha: não será por se imaginar que ela se foi desvirtuando a partir de uma origem imaculada, e que por isso terá hoje menos capacidade de produzir filósofos como o que assina o texto, que a sua estrutura ou utilidade serão postas em causa. Essa constância da instituição parece assentar precisamente no fato de ela mesma produzir as condições para que, geração após geração, os livres-pensadores reproduzam o discurso da sua inexorável decadência.

Existe aqui um paradoxo suplementar: nunca se tem a certeza absoluta se o filósofo deseja uma escola onde se produzam pensadores como ele, tornando assim o seu estado de exceção e de denúncia uma coisa obsoleta; ou se prefere esse mesmo estado de privilégio a partir do qual pode civicamente denunciar as imperfeições de uma instituição sempre em crise porque sempre em falta. 0 que acontece no referido artigo é algo que se verifica periodicamente no espaço público: solicitar-se, a quem tenha por ofício uma atividade intelectual, uma intervenção de cariz cívico sobre problemas que nos afetam a todos. Estamos, nesse caso, perante todo o peso da autoridade conferida pela identidade: filósofo. No entanto, o que ele nos diz é tão facilmente reconhecível por todos como o conteúdo de uma conversa corriqueira sobre a atualidade. Por que aceitamos ouvir o que já sabemos na fala dos nossos intelectuais? E como é que essa fixação do intelectual a um lugar identitário e de autoridade faz parte, muito para além dele próprio, de um problema geral de rarefação da escrita?

Tudo se passa como se convivessem pacificamente a dimensão do pensador como criador, ou sujeito de um ato de criação escrita, e a dimensão do sábio enquanto autoridade que tem algo a dizer sobre e pelos outros. Como se existisse uma ponte, pouco discutida na academia, entre o medo de errar do aprendiz e a segurança de si mesmo daquele que ocupa o lugar de autoridade. Em situações distintas, ambos tendem a contornar a escrita a favor da escrevência:

A escrevência seria o estilo daquele que escreve julgando que a linguagem não é mais do que um instrumento e que não tem que se debater com a sua própria enunciação; a escrevência é o estilo daquele que recusa propor o problema da enunciação e julga que escrever é apenas encadear enunciados. [...] Nesse caso não há, evidentemente, texto. (BARTHES, 1974, p. 31)

0 escrevente de Barthes seria aquele que não põe em risco a solidez da sua própria condição de sujeito pleno; aquele cujo movimento de escrita não desloca consigo o sujeito e as suas mais empedernidas convicções: aquele que não está, no fim de contas, envolvido no ato de escrita.

Ao confrontar-se com a imensidão de um projeto de escrita que o assusta, o investigador de pós-graduação desorganiza-se, aflige-se, em muitos casos, desiste. Mas, quando não o faz, sente-se logicamente atraído pela segurança de dizer a coisa certa: é nos autores que lê e que foram já reconhecidos, autorizados, ou até mesmo no orientador de tese, que espera ouvir a voz da ordem que organize finalmente a sua escrita. 
Mas também o filósofo ecoa a coisa certa, porque também ele pede emprestado à escola o discurso que há quase dois séculos a propaga e fortalece: o discurso decadentista, voz da sua própria idealização. Também ele contorna a escrita, embarcando na reiteração de um diagnóstico que não mais cessou de reverberar no debate público desde que as elites intelectuais do século XIX o formularam, na mesma centúria em que se fundou e delegou o projeto da escola pública para a posteridade.

Julgamos que o único refúgio entre a angústia da solidão de quem está a começar e a certeza do sábio que se autoriza e é autorizado a falar de tudo no espaço público - exceto da sua condição enquanto autoridade ou das suas dificuldades de escrita - é a aceitação do jogo do erro e da errância de escrever, essa aventura difícil para a qual precisamos mais de companheiros e ouvidos críticos do que de donos da verdade. Entendemos que o investigador carece disso mesmo - dessa concentração nos aspectos propriamente artesanais da escrita: ter coragem de abandonar uma ideia, experimentar diferentes abordagens a um problema, deixar os problemas transitarem para o interior de outros, não ter medo de dizer qualquer coisa ao lado para se conseguir proteger; para não fracassar perante os desafios de uma experiência que ainda não deixou de ser, na essência, uma experiência da solidão. Porque, precisamente, não existe um fora dessa escola que faz de todos nós aprendizes angustiados e filósofos da banalidade.

\section{O medo do gênio: para um combate} à solidão na escrita acadêmica

Nessa reflexão, configuram-se duas novas interrogações que se acoplam aos mesmos problemas de escrita enunciados anteriormente: De que é feito o nosso medo da escrita? Como enfrentar a sua solidão? A partir de uma investigação a respeito da ideia de gênio no ensino musical, interpela-se a vontade de escrever do ponto de vista dos impedimentos causados pelo medo de ser incapaz e pela solidão a que remete a escrita acadêmica.
0 conceito de gênio como revelia à instituição escolar instituiu-se algures nos finais do século XVIII. Difundido a partir do romantismo alemão, vigora ainda hoje. Mas a vinculação entre o gênio e o escolar exprime-se numa falsa relação de confronto, uma vez que esse gênio que parece escapar à formalidade das aprendizagens não existiria como fenômeno fora da linguagem escolar.

Quando se analisa historicamente o conceito e se almeja reconstituir a sua semântica, em particular no Portugal dos finais do século XIX a inícios do século XX, recupera-se um núcleo de significados onde cada gênio musical foi sendo construído numa sobreposição de justificativas dessa genialidade. Escapar a uma historiografia secular que mais não faz senão reificar, sem questionamento, a galeria de gênios implica desde logo ver o gênio atribuído a cada indivíduo como uma modalidade de expressão, entre outras possíveis. Desse modo, olhar para o gênio como uma discursividade obriga a desocultar o produto acabado em que se tornou e apreender os modos como foi produzido. Assim se descobre no gênio o mais perfeito aprendiz, aquele que dispensa a escola porque já incorporou a sua gramática.

Esse segundo exercício de escrita interroga a formação do escolar a partir do caso do ensino especializado de música e procura as regras implícitas no jogo discursivo a partir da construção de um suplemento da realidade, o gênio. A investigação genealógica de Ensino da música em Portugal (1868-1930): uma história de pedagogia e do imaginário musical incide, desse modo, em contraluz sobre o ideário comum a toda a pedagogia moderna, verificando que essa encontrou formas altamente eficazes de rarefazer a excelência educativa.

Por meio dessa imagem do gênio - polissêmica, difusa, modelar - articulase um quadro orgânico do todo do ensino musical, estabelecido entre dois aparentes contrários, onde se estipendiam, de um lado, o pensamento científico sobre o ensino musical, traduzido pela psicopedagogia, e, de outro, o 
imaginário engendrado no seio de profissionais e especialistas da música como musicistas, críticos, historiadores ou musicólogos.

0 ensino musical, porque careceu sempre de uma utensilagem técnica e de uma didática do singular, encontra-se assim aparentemente afastado do grande modelo da escola moderna de massas. Mas, ao indexar os conceitos que configuram ensino regular e ensino especializado, evidencia-se a formação de um mesmo escolar. Esses conceitos, que sujeitam todos os alunos ao gênio modelar, traduzem também a posição de sábio e de aprendiz face ao produto acabado: a noção de talento é talvez a mais pungente. Porém, antes de avançar para essa torção do texto sobre si mesmo, a tese obriga a explicitar brevemente a sua argumentação.

Mantido periférico sob todos os regimes e políticas culturais, o ensino especializado de música foi planeado originalmente para órfãos e populações em risco, primeiro no seio do ensino religioso e, após a revolução liberal de 1834, na Real Casa Pia de Lisboa. 0 escopo das nossas teses desenha uma breve tangente. Ao longo do século XIX, o ensino musical foi ocupado pelas elites, mantendo-se numa ambivalência de finalidades educativas de que somos herdeiros. Por um lado, albergou a formação de âmbito profissional que a Escola de Música do Conservatório Real de Lisboa, criada logo de seguida, fornecia aos seus alunos. Paralelamente, emergiu pela segunda metade do século XIX uma população de alunos externos, de forte densidade feminina e de origem social de classe média alta que aspirava a uma educação cultural de alto nível, embora sem intenção de seguir uma carreira profissional. Novamente se estreitam os laços das duas teses ao encontrar aqui um problema eminentemente populacional: o conservatório, a partir do século XX, não podia manter a sua qualidade formativa, uma vez que implodia sob o excesso de alunos. Na raiz desse tema, encontram-se, por um lado, as medidas de restrição na entrada de alunos vocacionados na escola oficial do Estado e, por outro lado, a aplicação de medidas de expansão de uma educação musical na escola primária e secundária destinada a todos os alunos e independente das qualidades pessoais.

0 cenário dos debates entre políticas educativas por meio do prisma da ideação do gênio musical, na figura do aluno e ou do mestre de exceção, permite então introduzir o foco do problema na observação dos bloqueios verificados nos processos de produção e transmissão cultural. Com efeito, ao longo do século XIX, ao mesmo tempo que o campo musical ganhava força e se autonomizava, expandia-se também, no seio de todo o campo cultural, uma outra tecnologia altamente policial. 0 gênio aparecia, assim, como uma ideia que, vinda do universo culto, invadiu o mundo escolar e passou a constituir o horizonte de vida de cada um dos alunos.

No ensino musical, sobretudo a partir do início do século XX, além do binómio amador/ profissional que nos chega desde a antiguidade clássica, passou a almejar-se um novo perfil de músico, menos técnico e mais intelectual. Para tanto, foram introduzidas disciplinas de cultura nos currículos do conservatório, medida que sustentou a demanda para que o musicista ocupasse as mais altas esferas da performance artística pela sua proximidade natural ao gênio, atitude reclamada pela recém-formada expertise musical portuguesa.

Gênio constitui, assim, uma tecnologia, uma vez que traça uma fronteira - ideal porque inalcançável, pragmática porque traduzida em modelos - para o ensino musical a partir de uma constelação de conceitos (talento, dom, virtuosidade) que peleiam constantemente entre uma das prerrogativas que a modernidade pedagógica reclamou para si: a possibilidade de sobrelevar o inato pela aprendizagem.

Apresentados a traços largos tanto o problema central como as ramificações essenciais da segunda tese que compõe esta digressão, podemos avançar para os problemas de escrita colocados por esse novo exercício e por esse percurso. Impõe-se primeiro aquele 
em que a análise histórica do gênio permite entender as condições de possibilidade desse medo que o aprendiz sente diante da escrita.

Desenha-se assim uma confluência entre o problema investigativo e a redação da tese. Configuram ambos um gesto que trai a relação do sujeito do conhecimento com o seu objeto e em que o sábio-aprendiz, pelo fio do desejo, lançase metodologicamente numa relação fragmentada e em permanente digressão em relação ao objeto que circunscreve (BARTHES, 1977, p. 41).

Com efeito, um problema traçado no interior da própria escola apela sempre para uma experiência escolar - mesmo que, no presente caso, os autores não conheçam inteiramente a experiência da vida sobre a qual investigam. 0 sábio-aprendiz habita assim em consciência um ínfimo da escola do presente, o que significa que, colocado numa mesma plataforma do escolar, está algures num plano de frontalidade face ao órfão e ao aluno de música do passado. A posição dessa escrita é de posteridade - e não de exterioridade em relação ao que investiga. Nessa contiguidade, parece supérfluo acrescer uma história de vida exterior à própria instituição escolar. Quando se trata tão simplesmente de afirmar a existência de possíveis fragmentos-outros no interior de um mesmo objeto, engendrar uma história sobre as razões de escrever uma tese torna-se uma forma teleológica de chegar a justificar o objeto máximo de desejo. 0 sábio-aprendiz desdobra-se.

Diríamos desse modo o que já tantos problematizaram: é porque está no interior de um discurso e de uma narrativa de experiência que o sujeito que quer conhecer não pode senão falar do que já é conhecido. A ousadia de olhar a experiência histórica de um ensino especializado ou corretivo sem o ter experimentado surge, assim, menos como ampliação de poder do discurso acadêmico que tudo poderia dizer, e mais como uma conexão.

Indica-se aqui o problema da quase impotência de manter uma exterioridade à linguagem, exercício apenas concebível num tempo efêmero. 0 mote dos problemas de tese apresentados revela bem uma ligação constante que remete para um desejo de ir e vir permanente em relação ao núcleo central da escola que habitamos e que inevitavelmente nos habita, como uma marca de um segundo nascimento. Todo o ritual de vida e morte metamorfoseia aqui a relação com a linguagem, ou com as diversas linguagens que nos constituem. Ao falar de nós como sujeitos de conhecimento, é do idioma escolar e do nosso permanente devir como escolares que fazemos uso. Na aplicação constante e no modus operandi da linguagem em que nos desdobramos em tempo contínuo, deixou de ser possível cortar o cordão umbilical, "estamos na escola e esta é ainda a nossa condição de possibilidade de pensamento e da escrita" (CAMARG0, 2010, p. 30).

A pesquisa aparece como a forma "em que se ensina o que não se sabe" (BARTHES, 1977 , p. 17), aquela em que o sujeito se deixa afetar pela busca, é toda ela máquina-desejante, e, nesse sentido, apela a um movimento de saída, de deslocamento em relação ao seu núcleo inicial. Perguntar assim como se constituíram tecnologias de linguagem escolar, que nos afetam permanentemente, envidase numa escrita que é ela mesma problema teórico-metodológico, obrigando a questionar o processo de conhecimento a partir de uma ótica do efeito da inventividade ou do estatuto imanado dos textos que realizamos (BARTHES, 1977; FOUCAULT, 1997). Tendo essa linguagem e essa escola como condição de possibilidade de conhecimento, a alegria ou a festa que o nosso desejo de conhecer constantemente veicula é o de admitir uma exterioridade à escrita pela própria escrita, ou à escola pela própria escola, e que demonstra que, de gênios e de órfãos, todos temos um pouco, por homogeneidade do processo linguístico de manufatura da nossa identidade ou modo de ser.

No imparável dispositivo da linguagem, descobre-se assim o gênio como tecnologia da produção artística e intelectual que tanto se move em direção à obra, como se afasta temporária ou definitivamente. Aí se encontram sábio e aprendiz no mesmo gênio musical. Toda 
a população escolar se reconhece e atua diante dessa tecnologia, que remete, paradoxalmente, à consciência de uma profunda solidão com que se vive o processo inventivo. Quando se vislumbra o seu modo de funcionamento ou se reconhece o poder da linguagem, fundam-se modos de “aligeirar esse poder" (BARTHES, 1977, p. 40), torna-se possivel afrontar a rarefação. Através de soluções locais e com regras impossíveis de prescrever universalmente (exempli gratia comunidades de escrita), o poder do gênio fica pelo menos suspenso e outras tecnologias podem interagir nas mãos do investigador.

$\mathrm{Na}$ nossa hipótese de escrita, importa menos que o aprendiz-sábio se desloque em relação ao gênio e ao polícia e se afaste deles, do que se situe, com essas figuras da autoridade e da ingenuidade, na zona intempestiva da crítica. Mas, antes de chegar a esse ponto estratégico da exposição, sublinhe-se que, na nossa opinião, qualquer pesquisa sobre o locus educativo que cria, necessariamente, uma exterioridade à própria escola a partir do seu interior, ao desvelar a panóplia de tecnologias e técnicas que, sendo transversais a toda a sociedade, levam a que o leitor neles se reconheça e estabeleça um renovado conhecimento sobre si mesmo, desinstalando os automatismos e os impensados inerentes à linguagem. Isso ocorre só em breves momentos e sob determinados pontos de aplicação. Só desse modo se pode conceber que o tema da orfandade marginal ou da genialidade, que arrastam inevitavelmente a questão da constituição do sujeito, faça sentido na operação de uma escrita da vida.

Lançar uma interrogação acerca da constituição discursiva do gênio musical na sociedade portuguesa de finais do século XIX e inícios do século XX permite divisar o processo social e tecnológico do que hoje seria a sua abjuração e, por um efeito de espelho, toldar os reflexos que a poderosa máquina da escrita lança sobre nós. No campo lexical estritamente artístico, gênio forma-se desde finais do século XIX como o suplemento que congrega diversas caraterísticas, tidas por naturais, relativamente comuns (talento, aptidão). Essas poderiam ser diagnosticadas, medidas e mesmo desenvolvidas, ao contrário do gênio, que escaparia a qualquer previsão lógica. Quando as fontes históricas confirmam a intuição sociológica de que também no talento se trocam causas por efeitos, o que significa que ele surge naturalmente em ambientes de grande familiaridade com a técnica (BOURDIEU, 1996), toda a engenharia do conceito de gênio passa a estar sob suspeita.

Com efeito, a atual literatura da psicologia e ciências da educação discute agora o gênio na sua forma denegada, através de conceitos satélite como talento musical, introduzindo uma variação sobre um núcleo essencial de problemas psicopedagógicos que no tempo histórico se colocaram frontal e indiscriminadamente.

Talento indexa agora uma série de descrições de comportamentos que sugerem tratar-se de um natural, mas sem rejeitar o peso da educação na constituição do talento. Outrora, também o gênio foi descrito nesses termos. Remetia para o acoplamento de uma forte exigência nas capacidades particulares de progressão para atingir um patamar individual de irrepreensibilidade técnica, e descrevia uma acumulação de grande número de horas diárias de prática musical, tanto em casa como nas escolas.

Assim, o patamar de excelência de artistas portugueses consagrados do século passado, como a violoncelista Guilhermina Suggia ou o pianista Viana da Mota, foi atingido, de acordo com os próprios, não apenas pelo seu talento natural, mas à custa de quatro a oito horas diárias de estudo do instrumento, até ao final da vida (POMBO, 1993; BRANCO, 1987). Como escreveu Benjamin a propósito do trabalho de escritor, "génio é trabalho diligente" (BENJAMIN, 2004, p. 12).

Conhecer as implicações do processo artístico genial suspende pelo menos momentaneamente a relação que faria do músico um talento acabado. Não se entrega a uma tarefa porque tem um talento, mas porque se entrega a uma tarefa enverga uma maestria que se designa 
por talento. Também o sábio-aprendiz alcança essa posição apenas na medida em que chega a admitir-se a exigência da entrega, e se concede uma relação privilegiada com o tempo.

0 enfrentamento dos medos e a diminuição que o sábio-aprendiz sente diante dessa figura desproporcionada e mítica viverá ainda acobertada. Afınal, o gênio mantevese como último mistério da criação apesar da modernidade. A própria linguagem científica que reitera o gênio na sua impossibilidade é a mesma que lhe contorna os limites e o torna mais palpável. Embora a tecnologia do gênio se tenha desenvolvido a partir da inscrição numa narrativa de vida, em Portugal, claramente desde os anos 1870, o caráter suplementar que essa noção apresentou diante da sua contemporaneidade, resguardou-o de qualquer prova. Só um exemplo de vida caraterizaria o gênio. Polissêmico, polivalente e polimorfo, coloca-se como linguagem indefetivel que articula o passado diretamente ao futuro. Num certo sentido, a noção de gênio é aquela que coloca o aluno em permanente devir, em consequente afastamento do seu presente. Suspender essa tecnologia pode ser restaurar o presente, o único tempo francamente necessário ao sábio-aprendiz.

Numa ética do encontro que dissolveria o medo da escrita, impõe-se ainda uma última aproximação entre o gênio músico e o labor do sábio-aprendiz: o desejo de uma obra criativa. A imposição da criatividade como valor máximo no mundo musical é recente e diz respeito à introdução da função-autor, primeiro na figura do compositor, mais tardiamente na do intérprete.

Num olhar nietzschiano, recente implicaria uma genealogia que revelasse como não se está diante de um natural, de um universal ou de um necessário, mas apenas que "chamamos conhecido às coisas a que nos habituamos" (NIETZSCHE, 2000, p. 241). Auxilia mais uma vez Espinosa, mostrando que um efeito se confundiu com uma causa (DELEUZE, 1988, p. 20). Diante dessa suspensão, Foucault coloca uma pertinente ponte para o sábio-aprendiz, entre a inventividade e a criação de uma novidade científica. Ao identificar criação com produção de conhecimento, mostra a pertinência de sinonímia entre conhecimento e inovação e repele, por seu antônimo, comentário ou repetição (FOUCAULT, 1997, p. 18-28). Tal exercício implica reconhecer que o sábio-aprendiz vive uma luta pelo poder com os pares e os mestres. Talvez a singularidade dessa posição se possa fazer diante de outras formas de combate, que sejam elas mesmas operadas pela criatividade - o aniquilamento que renova pela criação de uma posição-outra.

Essa mesma escrita perscrutadora dos mecanismos de linguagem que habitam na ideia de gênio demanda, por essa via, um trabalho específico do leitor como crítico, alguém que se coloca com. Leitor, aqui entendido como alguém que, da sua alteridade, procura ganhar o texto para uma comunidade maior do que a singularidade de quem o escreveu, mostra-se assim uma peça essencial para a formação de uma comunidade de escritores. Ele é um acelerador do tempo de reescrita. Se "escrever é o interminável, o incessante" (BLANCHOT, 2011:17), esse perpétuo movimento vive de uma batida de tempo curto, do recomeço convulsivo, que obriga a escrita à reescrita, o tempo que apenas para o gênio não escasseia.

Para o sábio-aprendiz, o leitor, o crítico ou o amigo trazem um tempo sincopado, exponenciado pelo amparo da crítica atenta, que se atravessa como atalho para dar asas ao tempo da criação. Tornado mais consistente, mais inteligível, mais forte na argumentação, na ilustração, o texto exposto ao movimento do pensamento célere quer tornar-se ainda mais curto. Para isso, demanda a crítica e todo o comentário que põe em crise o pensamento. Escavam-se então os abismos onde o pensamento desliza livremente, em velocidades. 0 tempo assim comprimido mostra-se um inesperado encaixe entre o gênio que o século XIX sagrou e a escrita potenciada pela crítica. Quase se poderia aventar que o sábio-aprendiz estaria tão mais próximo do gênio musical 
quanto tiver sido acompanhado na sua tarefa por uma comunidade de amigos.

\section{Além do polícia e do gênio: para uma coragem da escrita}

Ao longo deste percurso, imaginamos um lugar de discussão e artesanato da escrita de duas teses em História da Educação nos interstícios dos diversos automatismos da escrevência.

Na nossa perspetiva, conhecer as tecnologias da linguagem em que nos colocam tanto o policial como o gênio implica ganhar a possibilidade de lutar mais com a própria escrita pelo novo, e adotar uma escrita que se paute não pelo contra, mas pelo com. A escola do presente, à qual não somos exteriores senão pela força da pesquisa, pela potência da escrita e pelo embate da crítica, constitui-se como a própria força que move a narrativa.

Como se foi argumentando ao longo deste trabalho, a escola corresponde a uma comunidade de linguagem. Aí se instalou a plataforma de entendimento, de projeção no tempo futuro e passado, gramática comum e acessivel a todos, que possibilita o exercício da escrita inventiva. Essa modalidade não evita nem confronta a crítica, antes procura valer-se da infınita capacidade de restituição do texto, colocando os obstáculos ao processo de escrita identificados por cada um de nós no centro de uma autorreflexão conjunta. 0 sábio-aprendiz sabe afınal que a autoridade não é meramente atributo de mestres, nem a ingenuidade uma inerência de aprendizes. Ambas as qualidades funcionam mutuamente, sendo que uma não existe sem a outra. Ciente dessa mecânica, introduz nesse impensado, onde o sábio é ingênuo sobre o lugar de onde fala e o aprendiz ignora o que nele há de autoridade, uma possibilidade de afrontar os bloqueios da escrita.

Desse modo, não se faz crítica do uso da noção de gênio ou de polícia, faz-se crítica à escola do presente com a noção de gênio e com a noção de polícia. Radicalmente, a nós mesmos.

\section{Referências}

BARTHES, Roland. Escrever... Para quê? Para quem? Lisboa: Edições 70, 1974.

Aula. São Paulo: Cultrix, 1977

BATAILLE, Georges. A literatura e o mal. Lisboa: Vega, 1998.

BENJAMIN, Walter. Imagens de pensamento. Lisboa: Assírio \& Alvim, 2004.

BLANCHOT, Maurice. 0 espaço literário. Rio de Janeiro: Rocco, 2011.

BOURDIEU, Pierre. As regras da arte. Lisboa: Editorial Presença, 1996.

BRANCO, João. Viana da Mota. 2. ed. Lisboa: Fundação Calouste Gulbenkian, 1987.

CAMARGO, Danilo de. 0 ensaio e a escola: questões sobre a escrita, a crítica e a pesquisa em educação. In: LAUAND, Jean. (Org.). Filosofia e Educação. São Paulo: Factash, 2010, v. 17, p. 29-37.

CAMÕES, Luís de. Os Lusíadas. Lisboa: Instituto Camões, 2000.

DELEUZE, Gilles. Spinoza: practical philosophy. San Francisco: City Light Books, 1988. 
FOUCAULT, Michel. A ordem do discurso. Lisboa: Relógio d’Água, 1997.

GIL, José. A violência da ignorância. Visão, Lisboa, v. 17, n. 889, p. 26, 18 mar. 2010.

MARGIOCHI, Francisco Simões. 0 digno par Margiochi pede ao governo que não anua a um pedido da camara municipal, que tem por fim retirar do museu arqueológico do Carmo quatro estátuas que pertencem ao projetado monumento a D. Maria I. Atas da Câmara dos Pares do Reino. Sessão 30 abril 1898, p. 267-268. Disponível em: <http://debates.parlamento.pt/?pid=mc>. Acesso em: 30 ago. 2013.

NIETZSCHE, Friedrich. A gaia ciência. Lisboa: Guimarães, 2000.

NOGUEIRA, António Rodrigues. Orçamento do Ministério das Obras Públicas. Atas da Câmara dos Senhores Deputados da Nação Portuguesa. Sessão noturna, 4 maio 1903, p. 19. Disponível em: <http://debates.parlamento.pt/?pid=mc>. Acesso em: 30 ago. 2013.

Ó, Jorge Ramos do. 0 governo de si mesmo: modernidade pedagógica e encenações disciplinares do aluno liceal (ultimo quartel do século XIX - meados do século XX). Lisboa: Educa, 2003.

PAZ, Ana. Ensino da música em Portugal (1868-1930): uma história de pedagogia e do imaginário musical. Lisboa: Instituto de Educação da Universidade de Lisboa, 2013. Projeto de doutoramento. Documento não publicado.

POMBO, Fátima. Guilhermina suggia ou o violoncelo luxuriante. Porto: Fundação António Engenheiro de Almeida, 1993.

SARMENTO, Alexandre Tomás de Morais. Projeto de Lei para a extinção da Intendência-Geral da Polícia. Atas das Cortes Gerais e Extraordinárias da Nação Portuguesa. Sessão 30 janeiro 1822, p. 50-51. Disponível em: <http://debates.parlamento. pt/?pid=mc $>$. Acesso em: 30 ago. 2013.

VALLERA, Tomás. A polícia de todos e de cada um: a Casa Pia de Lisboa e o devir escolarizante do governo da vida (17801834): um roteiro de pesquisa em seis trajetos. Lisboa: Instituto de Educação da Universidade de Lisboa, 2012. Projeto de doutoramento. Documento não publicado.

Tomás Vallera é doutorando em História da Educação na Universidade de Lisboa, Portugal.

Ana Luísa Paz é doutoranda em História da Educação na Universidade de Lisboa, Portugal. 